\title{
Enchondroma of Distal Femur Treated With Curettage And Allograft And Autograft: A Rare Case Study.
}

\author{
Dr.Nilesh Kachnerkar ${ }^{1}$, Dr. Ghaniuzzoha Asadi ${ }^{2}$, Dr.Ramakant Bhivsan ${ }^{2}$ \\ ${ }^{1}$ (Assistant Professor, Department Of Orthopaedics, GMCH Aurangabad, India) \\ ${ }_{2}^{2}$ (Resident Doctor, Department Of Orthopaedics, GMCH Aurangabad, India) \\ ${ }_{2}^{2}$ (Resident Doctor, Department Of Orthopaedics, GMCH Aurangabad, India)
}

\begin{abstract}
The cartilage lesion in bones can be on the surface or inside the bone. Cartilage lesions in medullary cavity of bone is called Enchondroma. Enchondromas consists of 3-10\% of all bone tumours and 12-24\% of benign tumours. They are most commonly found in young age group and in bones of hands and feet. Malignant counterpart is called as chondrosarcoms. Presence of enchondromas in older age group and in atypical site leads to some degree of controversy as to the diagnosis and treatment of these lesions. We here present a case of 65 years male patient who presented with history of pain in left knee. Radiological examination and mri was done along with truecut biopsy. The patient was managed with curettage and bone graft of autologic and allogenic source. Histopathology confirmed the lesion to be Enchondroma. At the latest follow up the patient was symptom free and there was no evidence of any recurrence.
\end{abstract}

Keywords : combination of allograft and autograft, Enchondroma, rare site distal femur.

\section{Introduction}

Enchondroma (chondromyxoma) is a solitary intramedullary benign tumour composed of matured cartilage , that is usually found in the short tubular bones of hands and feet .In 50\% cases it is found in bones of hand and younger age group. We report rare case of enchondroma in 65 year old patient at distal femur treated with curettage and combined autogenic and allogenic bone graft. Previously there is no paper of this combination of treatment at rare site.

\section{Case Report}

A 60 year male presented to our hospital with a history of pain in left knee and inability to walk since 4 months. Patient gave history of constant dull aching type pain incidious in onset, moderate degree, non radiating . Pain aggravated on standing and walking and relieved on taking rest and analgesics. The general examination was unremarkable with no significant proximal lymphadenopathy and distal neurovascular defecit Local examination reveled tenderness over lateral condyle of left femur with full range of movement with no skin changes and no local rise of temperature. Radiological examination with $\mathrm{x}$ ray of distal femur revealed a large well demarcated lobulated lytic subcondral lesion with cortical thinning in distal femur with intralesional calcification without extension in joint. MRI showed it to be Aneurysmal bone cyst with minimal soft tissue involvement. So a truecut biopsy was done to confirm the diagnosis which showed it to be Enchondroma.

Patient underwent curettage and autogenic and allogenic bone graft. The patient was put in supine position under spinal anesthesia, a lateral incision was take on distal femur, lesion was exposed and tumour was removed through a lateral bone window and through curettage was done. Then auto bone graft was harvested from ipsilateral iliac crest. This autogenic bone graft along with allogenic bone graft from bone bank was filled in the tumour cavity, insion was closed in layers. Tumour curetted were sent for histopathological analysis . Static quadriceps and knee range of movement exercises were started on day one postoperatively . Sutures were removed after 2 weeks and allowed to do partial weight bearing from 6 weeks gradually increasing to complete weight bearing over next 3 months. Histopathological report showed mature cartiaiginious cap over mature bone, confirming the diagnosis .

\section{Discussion}

Presence of pathology in distal femur arouses suspicion of various other differential diagnosis like giant cell tumour, aneurismal bone cyst, chondroblastoma, chondrosarcoma, hence Enchondroma should also be kept in mind [ 1]The enchondroma healed without recurrence. Usually either allograft or allograft is used to fill the defect, in our case it is one of the rarest reported cases of distal femur enchondroma where a combination of allograft and autograft were used successfully.[2,3] Enchondromas are usually more common between 10-50 years of age, and most common locations are small tubular bones of hand and feet. Our case is rare in the sense the age of the patient is 65 years and found at rare location of distal femur.[4,5] The differentiation of benign from malignant cartilaginous tumours is one of the most difficult problems in bone 
pathology. In our case study the clinical diagnosis was more in favour of malignancy, mri report showing diagnosis of Aneurysmal Bone Cyst and finally the confirmatory diagnosis on histopathological examination came out to be Enchondroma.[4,5].

It is often diffucult to distinguish enchondromas from low grade chondrosarcomas.(6)

\section{Figures}

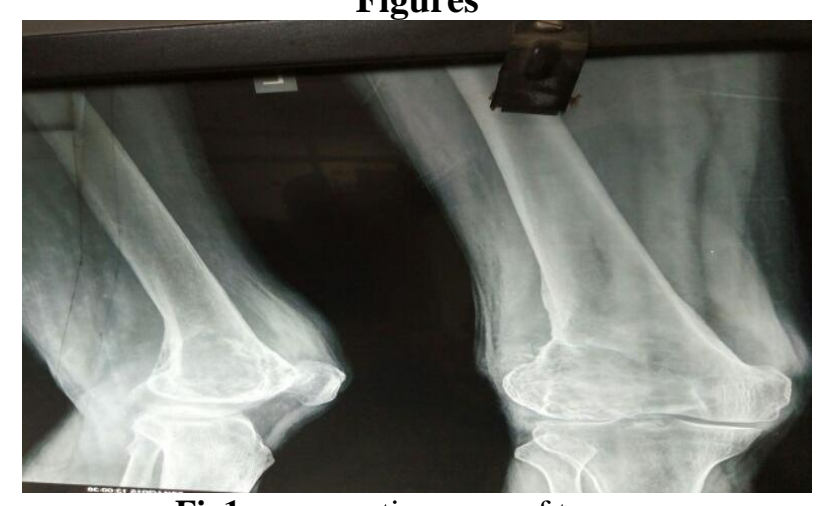

Fig1: preoperative $\mathrm{x}$ ray of tumour

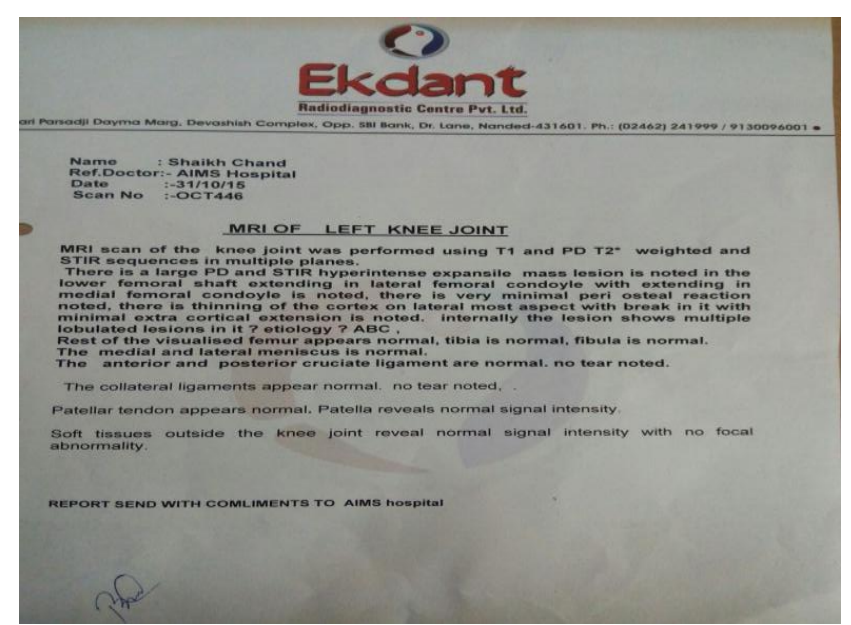

Fig2: mri study report showing it to be aneurismal bone cyst

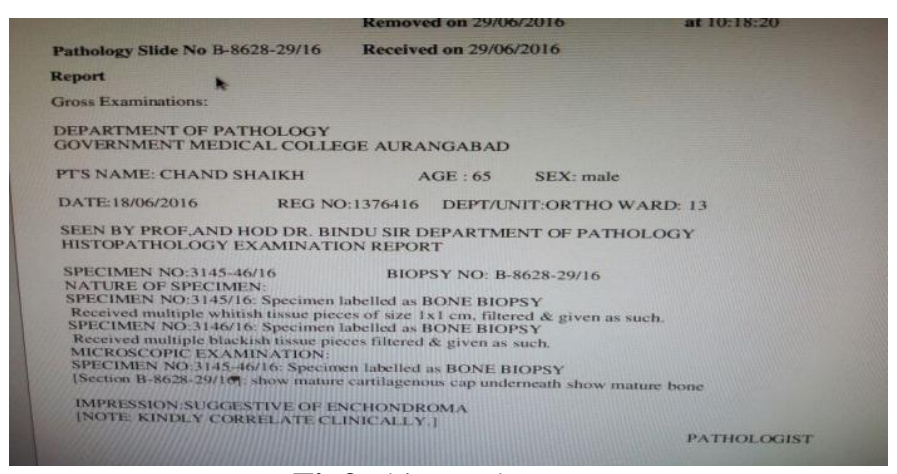

Fig3 : histopath report 


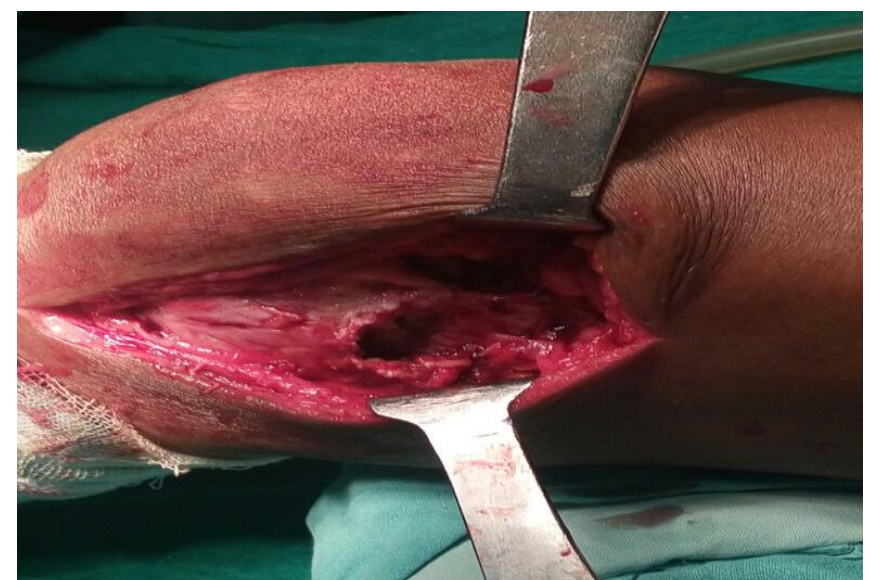

Fig4: intraoperative image showing bone window for curettage

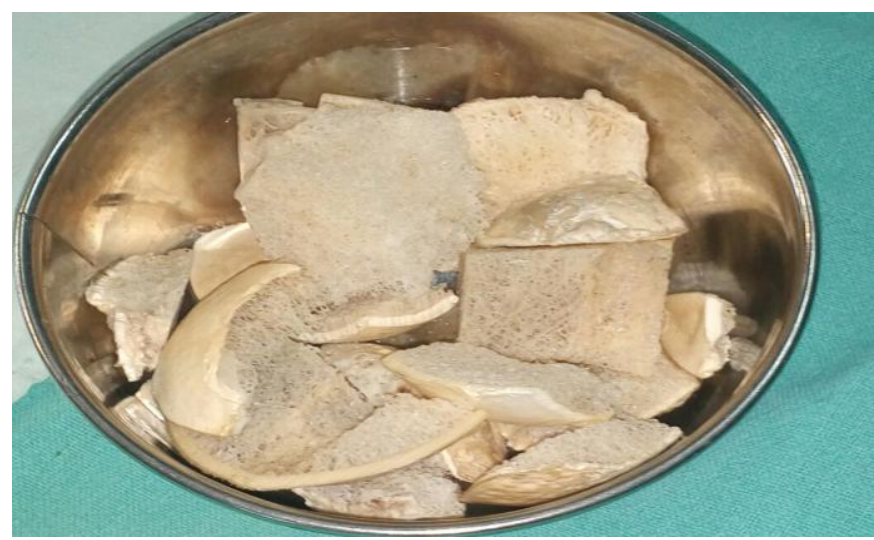

Fig5: bone allograft procured from bone bank

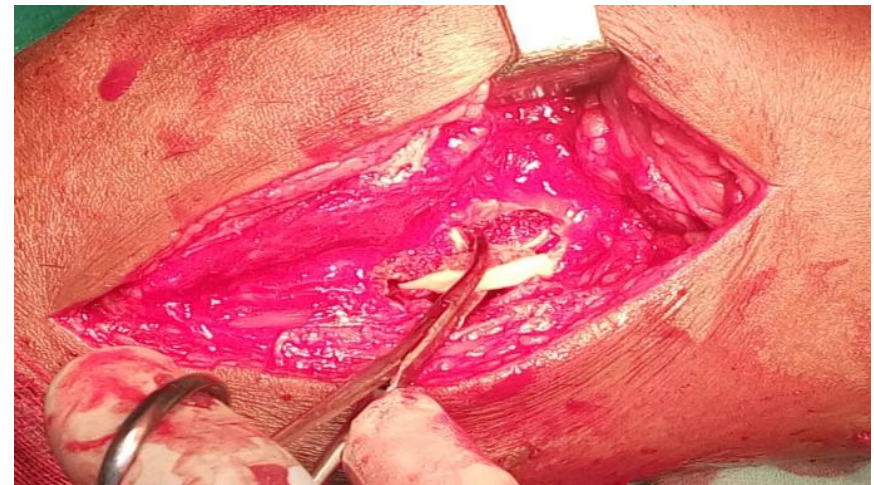

Fig6: intraoperative autograft inserted

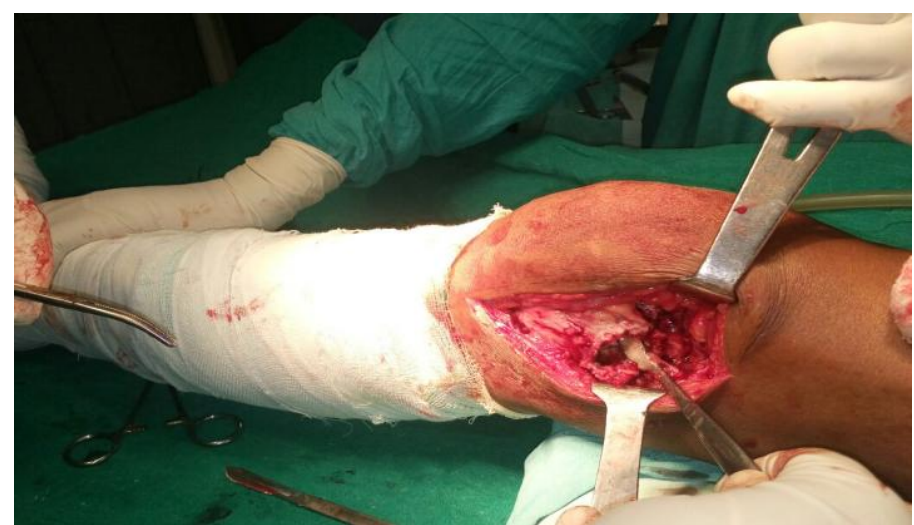

Fig7: intraoperative bone allograft inserted 


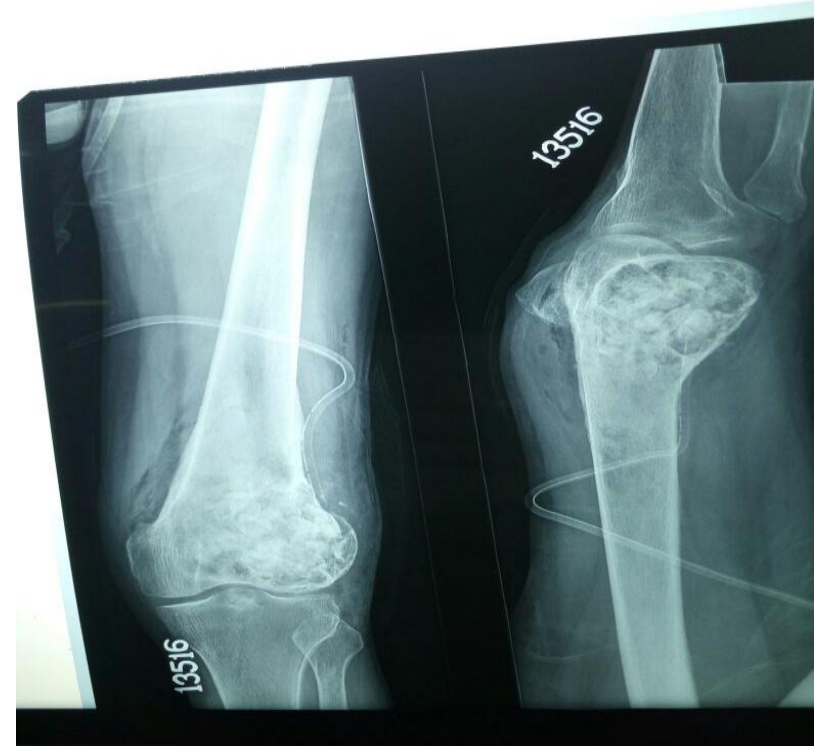

Fig8 : post operative $\mathrm{x}$ ray showing drain in situ

\section{Conclusion}

This case study reports the presentation of atypical enchondroma presenting in a 65 year old male at a rare site of distal femur in long bone. Enchondroma was differentiated from malignant tumour and other differential diagnosis and treated by curettage and combination autogenic bone grft with allogenic bone graft . This case study will help future researchers to study enchondromas with atypical character, differentiate it from malignancy and try out other combinations of newer modalities of treatment

\section{Acknowledgements}

Authors sincere thanks to the patients who have thought us so much .

\section{References}

[1]. Walden MJ ,Murphy MD , Vidal JA , Incidental enchondromas of the knee. AJR Am Roentgenol , 2008 ,190(6):1611-15

[2]. Edward M , Jewusiak, Kenneth F Spence, Kenneth W Sell . Solitary Benign Enchondroma Of The Long Bones Of The Hand . JBJS Am 1971 Dec 53(8) 1587-1590

[3]. Yalcinkaya M, Akman YE, Bagatur AE . Recurrent Metacarpal Enchondroma Treated With Strut Allograft 14 Year Follow Up. Pubmed orthopedics, 2015 july 1, 38(7) e647-50.

[4]. Campbells Operative Orthopaedics , 12 th edition, Tumours . Benign Bone Tumours And Nonneoplastic Conditions Simulating Bone Tumours, Vol 1, S Terry Canale, James H Beaty, Page 865.

[5]. Tureks Orthopaedics : Principles and their Application, $4^{\text {th }}$ edition, Vol 1, Samuel L Turek, Page 599.

[6]. Kendell SD, Collons MS, Arkins MC, Sundaram M, Tinny KK . Radiographic differentiation of enchondroma from low grade chondrosarcoma in the fibula. Skeletal Radiology , 2004,33(8):1432-2161. 